\title{
Evaluating the Study Abroad Experience using the framework of Rotter's Social Learning Theory
}

\section{Mark McLeod \\ Vince Carter \\ Steve Nowicki \\ Dana Tottenham \\ Philip Wainwright \\ Dana Wyner \\ Emory University}

The goal of most if not all study abroad programs is to provide students with a set of life experiences that will broaden their perspectives and expectations and have a positive impact on the way they live and think. In their public descriptions of the study abroad programs, administrators suggest they seek to accomplish valuable goals such as: "intellectual and personal growth via challenging student scholarship and cultural engagement" (Emory University, 2015; http://cipa.emory.edu/contact/emorystudyabroad/index.html). Universities and third-party program providers use targeted language to market their programs to prospective students, including the notion that study abroad creates "once-in-a-lifetime adventures that transcends expectations. Our goal is to rock the world of some 6,000 study abroad students every year" (IES 2015; http://www.iesabroad.org/study-abroad/about). Similarly, the Council on International Educational Exchange's (CIEE) website states, "We're dedicated to sponsorship, outreach, and community projects centered on education, leadership, and access to transformative educational experiences" (http://www.ciee.org/believe/).

Over the past decade, the education abroad field has experienced tremendous growth, diversification and complexity. This expansion has included not only increased numbers of students studying abroad, but also a lens on diversity initiatives, new professional organizations dedicated to quality enhancement, development of strategic initiatives for the internationalization of higher education, and an increase of rigorous research for the field as a whole. According to NAFSA: Association of International Education, "Professionals in the field of international education and exchange are expressing a growing interest and need for specialized knowledge, research, and synthesis of emerging perspectives in a wide range of disciplines and fields" (NAFSA, 2015). Current research initiatives in education abroad range from issues of global citizenship (Lewin, 2009), learning outcomes (Vande Berg, et al., 2012), intercultural competence (Deardorff, 2009), and models for curriculum and career integration (Johnson \& Hindbjorgen, 2015).

As the study abroad field grows more sophisticated, so too does the need for empirical research to evaluate and describe the impact of this experience for students. Many study abroad programs assess the experience through personal testimonials, face-valid techniques of data such as the number of participants, and student responses to post-program evaluations (Engle \& Engle, 2003; McLeod \& Wainwright, 2009). It may be easy to imagine that experiencing other cultures in all their richness will have a positive impact on a student's life, but the kind of face validity that is at times still passing for 
scientifically based evaluation is an inadequate substitute for reliable and valid research evidence to substantiate theoretical assumptions. Furthermore, there is a growing interest in applying theoretical frameworks from other disciplines to the field of study abroad to support the research agenda. In this spirit, McLeod and Wainwright (2009) and others, e.g. Murphy, Sahakyan, Doua and Sieloff Magnan (2014) and Hadis (2005), have suggested rigorous means should be used to fully evaluate the impact of the study abroad experience upon participants. Engle and Engle (2003) agree and suggested that "study abroad educators and administrators should....re-orient their focus from an appraisal of the sheer numbers of students participating in international education to the quality and impact of their experiences abroad" (p. 1).

This research study proposes to use Rotter's well-established and relevant Social Learning Theory (SLT) (Rotter, 1954, 1982) as a framework to guide and to evaluate significant components of the study abroad experience. As higher education institutions emphasize the critical need for expanding international programs, it is imperative that administrators seek to validate these programs' impact on the most important constituents: the students. Vande Berg, et al. (2012) have reviewed research that focuses on the learning of academic subject matter. In taking this research agenda a step further, what affect do study abroad programs have on students' personalities and in turn their academic achievement? The present study applies one of most effective and well known learning theories, Rotter's Social Learning Theory, to the student experience while studying abroad.

SLT has been the stimulus for literally thousands of studies investigating a wide range of human behavior including personal adjustment and academic achievement (Ammirati \& Nowicki, in press; Kalechstein \& Nowicki, 1997; Marshall \& Brown, 2004) and because it emphasizes learning as the major mechanism of behavioral change it provides an appropriate framework and perspective for evaluating individuals in study abroad programs. A key component of SLT, expectancies, is consistent with the ideas offered by Engle and Engle (2003) who proposed categorizing programs on the basis of what students should "expect" from their study abroad experience with the hope that matching expectancies with realities would lead to a more positive experience. However, our knowledge of the worth of this assumption is limited due to minimal research that has measured relevant student expectancies, examined whether study abroad programs impact these expectancies, or considered the other psychologically important and testable constructs such as self-esteem. The purpose of this study is to examine the effect of study abroad programs on participants' expectancies of personal control and their self-esteem.

\section{Social Learning Theory}

Social learning theory proposes that human behavior can be predicted by two general factors, (1) the expectancies people have that if they behave in a certain way they will be rewarded and (2) how much they value the reward they are attempting to acquire (Lefcourt, 1981; Rotter, 1954). One of the most important and well-researched expectancies within this theory is called Locus of Control (LOC). LOC reflects the extent to which people see a connection between what they do and what happens to them. The more individuals perceive that these connections exist the more internally controlled they are. On the other hand, the less they tend to see connections between what they do and what happens to them, but instead view what happens to them as the result of luck, fate, chance or powerful others, the more externally controlled they are (Rotter, 1966). LOC does not divide people into a dichotomy, but rather describes a continuum that ranges from complete internality to total externality. 
Based on the results of thousands of studies, it has been found that internals do better than externals especially in unstructured, ambiguous or novel situations where they must rely on their own skills to solve problems, while externally controlled individuals appear to do better when the situations are more structured and they are given specific instructions for how to behave (Ammirati \& Nowicki, in press; Nowicki \& Duke, 1983; Rotter 1966). According to SLT because the study abroad experience is a novel and ambiguous one for most participants it will accentuate the differences between internals and externals and how they react to the program.

\section{Focus Group Findings}

In order to learn more about students' study abroad program experiences in general and in terms of their expectancies, McLeod and Wainwright (2009) gathered information from several focus groups in two locations; one English speaking (St. Andrews, Scotland) and one French speaking (Paris, France). They found that the manner in which student expectancies were either met or unmet significantly related to how students felt about the experience and themselves. Students who initially expected to have a very positive experience abroad often reported that they were disappointed by how difficult it was for them to adjust. For those students who eventually had a positive ending experience, the initial stage of disappointment was often what led them to, as one student put it, "Feel like I could handle just about anything." What seemed to separate those students who ended positively from the few who did not was whether or not they had experienced increased confidence in their ability to have an impact on their environment, a feeling state consistent with an internal locus of control.

In addition to feeling more positive about their ability to impact on what happened to them, at the end of their study abroad experience, students who participated in the focus group discussions and who had successful experiences studying abroad also reported increased self-esteem and selfworth.

\section{Present Study}

The purpose of the present study was to examine the impact of the study abroad experience on the participants' locus of control and self-esteem. Based on Rotter's SLT it was predicted that students who participated in study abroad would become more internal as a result of that experience. In addition, while participants' self-esteem may decrease at first as students adjust to their new surroundings, it was predicted that self-esteem should improve by the end of the experience as students learn better coping skills and how to adjust to their new environments.

\section{Method}

\section{Participants}

The participants were college undergraduates who were studying abroad ( $n=100$; males $n=15$, females $n=85$ ) and the comparison group of students who were taking a spring semester psychology lecture class $(\mathrm{n}=128$; males $\mathrm{n}=27$, females $\mathrm{n}=101)$.

\section{Measures}

Locus of Control: The Adult Nowicki Strickland Internal External Control scale (ANSIE) was used to measure Locus of Control (Nowicki \& Duke, 1974). The scale consists of 40 items that were answered yes or no. The test has been used in nearly a thousand studies and has acceptable estimates of internal consistency and test-retest reliability (Nowicki, 2014). It has been shown to be related to 
academic achievement, persistence, information processing and personal adjustment (Nowicki, 2014).

Self-Esteem: This was measured via the Rosenberg Self-Esteem Scale (Rosenberg, 1965). The scale is made up of ten items. Respondents answer each item on a four point scale (strongly agree, agree, disagree, strongly disagree). Scores can range from ten to 40 . The test has been used in a wide variety of studies that attest to its construct validity. For example, Fleming and Courtney (1984) found that it was negatively related to low indices of self-esteem such as anxiety, depression and anomie. It showed an internal consistency via Cronbach's alpha of .84 and a test-retest reliability over a week of .85 in the same study.

Procedure: The experimental group was made up of three cohorts of college undergraduates, each cohort was obtained over three consecutive academic years and each consisted of students studying abroad that particular year. Similarly, the control group consisted of three cohorts, each cohort obtained in the same three consecutive academic years and same semester as the experimental group. Thus, over a three year period, each study abroad cohort had a corollary control group obtained from an undergraduate psychology class. An attempt was made to have the students in each group be as close as possible to the same age, and year in school. All participants were asked via email solicitations to complete locus of control and self-esteem measures at the beginning, mid-way through, and at the end of the semester. In addition, they were asked to complete the measures six months following the end of that semester. Emails were worded in the following way:

Dear Student, Thank you for your prior participation in our study of how various classroom experiences impact Emory students. As we mentioned in the pre-departure orientation last spring, your participation is extremely important to us. Students who participate in the study will be entered into a raffle to be eligible to receive gift cards for up to $\$ 300$. Please click on the link below to review the consent statement and submit the next survey. http://vovici.com/1.dll/JGsB6B6B6C672lzD9MU804210J.htm

The survey takes approximately 10 minutes to complete. You will receive a follow-up survey in December 2012 and July 2013. Students who complete all the surveys will be automatically entered to win the raffle.

Thank you for your participation.

Sincerely,

Center for International Programs Abroad

While conducting the surveys there was a university based switch from the Vovici survey tool to Qualtrics, and there was not enough time to save all of the information that was stored in Vovici. As a result, it is impossible to say exactly how many invitations and reminders were sent out, or precisely when all of them were sent. However, the time frames reported above are generally correct. In addition, while running the second cohort computer glitches resulted in the midsemester solicitation being aborted. For this reason, one of the analyses was run without using this cohort.

Due to the nature of the email solicitations, it was not possible to obtain compliance for all subjects. Consequently the makeup of responses from each solicitation consisted of differing 
groups of individuals. We were able to isolate a reduced pool of subjects who all participated in every email solicitation (Table 2).

\section{Results}

Results from analyses of variance provided support for the hypothesis that the study abroad experience would have a positive effect on the participants in terms of their locus of control. However, statistical analyses revealed that self-esteem was not significantly affected by the abroad experience.

Table 1 presents the means and standard deviations of locus of control and self-esteem scores for the pre-, post and follow up time periods. In terms of locus of control, while the differences between the study abroad and comparison groups differed marginally at the pre $(t(98)=-.51)$, and post $(t(85)=-1.12)$ testing periods they rose to significance at follow up $(t(79)=-2.26, p<.03)$. This suggests that compared to typical students matriculating in college, study abroad students became more internal as the result of their experience and maintained the change in internality for at least six months after they returned to their colleges.

On the other hand, examination of the self-esteem scores showed that both study abroad and typical students remained essentially the same over time. Students choosing to go on the study abroad program were higher in self-esteem to begin with and the study abroad experience did not significantly increase that difference over time.

Table 1. Means and standard deviations in locus of control and self-esteem of total study abroad and control group students

\begin{tabular}{|c|c|c|c|c|c|}
\hline \multirow[b]{2}{*}{ Measure } & \multirow[b]{2}{*}{ Time } & \multicolumn{2}{|c|}{ Study Abroad } & \multicolumn{2}{|c|}{ Control } \\
\hline & & $n$ & $M(S D)$ & $n$ & $M(S D)$ \\
\hline \multicolumn{6}{|c|}{ Self-Esteem } \\
\hline & Pre & 100 & $23.45(4.52)$ & 128 & $20.98(5.19)$ \\
\hline & Post & 87 & $22.74(4.49)$ & 64 & $20.98(5.68)$ \\
\hline & Follow Up & 81 & $23.09(4.74)$ & 75 & $20.52(5.33)$ \\
\hline \multicolumn{6}{|c|}{ Locus of Control } \\
\hline & Pre & 100 & $10.67(4.47)$ & 128 & $10.98(4.77)$ \\
\hline & Post & 87 & $9.22(4.51)$ & 64 & $10.06(4.72)$ \\
\hline & Follow Up & 81 & $9.89(4.97)$ & 75 & $11.60(4.46)$ \\
\hline
\end{tabular}

Table 1 presents the means and standard deviations of student responses from the pre-, postand follow up time periods. However the same students may not have participated in each of the testing periods so Table 2 presents the locus of control and self-esteem scores of those students who completed not only the three testings mentioned above but also a testing that took place midway in the program. The results show even more clearly the positive impact of the study abroad program on students' locus of control. In this case, the trend toward greater internality of study abroad students compared to their typical peers at the pre- and mid-term times becomes significant at the post time period $(t(18)=-2.25, p=<.05)$ and, more importantly, is maintained at follow up six months later $(t(18)=2.02, p=<.05)$.

Likewise Table 2 shows that self-esteem scores follow the same nonsignificant pattern as they did in Table 1. Study abroad students began the program with significantly higher self-esteem scores than typical students and that difference remained constant during and after the program was complete. 
Table 2. Means and standard deviation in locus of control and self-esteem in study abroad and control group who completed tests at every testing session

\begin{tabular}{|c|c|c|c|}
\hline \multirow[b]{2}{*}{ Measure } & \multirow[b]{2}{*}{ Time } & \multirow{2}{*}{$\begin{array}{l}\text { Study Abroad }(n=11) \\
M(S D)\end{array}$} & \multirow{2}{*}{$\begin{array}{l}\text { Control }(n=9) \\
M(S D)\end{array}$} \\
\hline & & & \\
\hline \multicolumn{4}{|c|}{ Self-Esteem } \\
\hline & Pre & $22.91(5.30)$ & $17.88(4.78)$ \\
\hline & Mid & $23.18(3.76)$ & $17.89(6.92)$ \\
\hline & Post & $23.64(3.78)$ & $18.00(5.94)$ \\
\hline & Follow Up & $23.91(4.74)$ & $18.00(4.82)$ \\
\hline \multicolumn{4}{|c|}{ Locus of Control } \\
\hline & Pre & $9.45(4.34)$ & $10.89(3.26)$ \\
\hline & Mid & $9.64(5.64)$ & $12.33(6.12)$ \\
\hline & Post & $7.27(3.13)$ & $11.67(5.50)$ \\
\hline & Follow Up & $7.82(2.75)$ & $12.33(6.22)$ \\
\hline
\end{tabular}

\section{Discussion}

In the present study, we found, as predicted, that participants in the study abroad programs gained significantly in internal locus of control compared to their typical peers who did not participate in the experience abroad. Possessing an increased internal LOC means that students are more likely to act in ways that will lead them to be more effective problem solvers. Research shows that internals tend to persist longer at tasks, delay gratification until tasks are completed and gather relevant task information more effectively (Rotter, 1966). As highlighted in the introduction, internality is associated with a variety of positive outcomes including better personal relationships and academic achievement. The outcomes of the present study show that as a result of the study abroad experience students returned to their colleges with greater internality and thus were better prepared to deal with whatever personal and academic challenges they would be facing. In this regard, it is important to note that the changes in LOC that had taken place by the end of the abroad experience were not fleeting but were still present six months later. It can be concluded that the study abroad experience made a substantial and long lasting favorable impact on the students.

Self-esteem scores did not change significantly more in the study abroad group than they did in the typical student comparison group. Study abroad students started out with higher self-esteem scores than their comparison peers and they maintained that difference at the end of the program and six months later. It may be that there was a ceiling effect. Self-esteem scores could only go so much higher. It is also possible that it might take more time for the increased internality to bring about the successes that would lead to greater self-esteem.

Regardless, it is important to note that self-esteem did not decrease for internals as a result of their becoming more aware that their behavior had more to do with what happened to them than they previously thought, i.e., an increase in internality. This is significant because increasing internality means that students were not only learning about behaviors that lead to success, but also behaviors that lead to failure. That is, students are becoming more aware of the role they play in both success and failure. In spite of that, their self-esteem was maintained.

The positive results of the current study suggest that continuing empirical research using the SLT framework may be warranted. For example, future studies following the SLT framework and the suggestion made by Engle and Engle (2003) should examine how much of the study abroad outcomes, positive and negative, are impacted by the closeness of the match between the structure of the 
program and the locus of control of the individual student as well as by including measures of the specific expectancies of study abroad participants. For example, we would predict that students who are relatively externally controlled might have more positive experiences in relatively more structured study abroad environments, as compared to internally controlled students (McLeod, 1985). If the association between locus of control and "structured-ness" of the program holds for study abroad participants then locus of control could be used to guide students to an appropriately structured program.

Students in the focus groups repeatedly suggested that violation of expectancies and the feeling of being forced to take risks with which they were uncomfortable were central to how they evaluated their experiences abroad. It would be interesting to examine more closely the impact of violating expectancies on self-esteem and locus of control (e.g. Boulay, 2004). For example, one might examine: (1) whether violating expectancies is a necessary catalyst for personal growth (e.g. improved selfesteem, increased internal locus of control), (2) whether or not there are ways to produce positive growth that are less stressful, and (3) how to better predict which students will be negatively impacted by such a violation of expectancies. To date, there appears to be little research effort directed to help guide study abroad programs in their efforts to both minimize pain and maximize the potential for positive growth.

We also think that demographic variables such as gender, ethnicity and country of ancestry would be useful areas of study to explore. We chose these latter three demographic characteristics because of the responses of the focus groups that they seemed to play an important role in students' expectations of what their study abroad experiences would be like and the fact that the preponderance of study abroad participants were women. For example, students studying abroad in a country of their family's heritage may tend to have much stronger emotional reactions to their experiences and perhaps higher expectations of a positive experience than students who did not have the same connection.

Because of the four decades of research tying internal locus of control and academic achievement together (Kalechstein \& Nowicki, 1997), future researchers should collect academic performance data from both study abroad and comparison control groups leading up to and following the study abroad experience. We would predict that as a result of their increased internality study abroad students would perform better academically as compared to a control group after they return from their experience. In addition, if the study abroad experience is a positive one, we might expect study abroad students to form a more positive relationship with the sponsoring university as compared to other students, and perhaps be more prone to show their support of that institution once they graduate in activities, connections, and financial contributions. These are all objective data that could easily be obtained to evaluate the impact of the study abroad experience.

Similarly, empirical research of study abroad programs could provide valuable information to relevant administrators for use in improving programming and increasing the likelihood of greater institutional "connectiveness" with the students. But perhaps more importantly, it could add to a richer understanding not only of what the study abroad programs impacts are, but also how they take place and how such information could be used for improvement. For a field that describes its programs as "transformational," continued research that documents and describes how this 
transformation takes place is a worthy goal for all involved in this unique college experience.

\section{References}

Ammirati, R., \& Nowicki, S. (in press). Locus of Control. Oxford, UK: Oxford Bibliographies.

Boulay, B. A. (2004). "If at first you don't succeed..." The cognitive and affective benefits of experiencing failure. Dissertation Abstracts International Section A: Humanities and Social Sciences, 64(8A), 2776.

Deardoff, D. K., ed. (2009). The Sage Handbook of Intercultural Competence. Thousand Oaks, CA: SAGE Publications, Inc.

Engle, L., \& Engle, J. (2003). Study abroad levels: Toward a classification of program types. Frontiers: The Interdisciplinary Journal of Study Abroad, 9, 1-20.

Fleming, J. S., \& Courtney, B. E. (1984). The dimensionality of self-esteem. II. Hierarchical facet model for revised measurement scale. Journal of personality and Social Psychology, 46, 404-421.

Hadis, B. F. (2005). Gauging the impact of study abroad: How to overcome the limitations of a singlecell design. Assessment \& Evaluation in Higher Education, 30, 3-19.

Johnson, M. \& Hindbjorgen, K. (2015). "Why career integration?” In Anderson, C., Christian, J., Hindbjorgen, K., Jambor-Smith, C., Johnson, M., \& Woolf, M., (eds.) Career Integration: Reviewing the Impact of Experience Abroad on Employment, Vol. I. (pp. 14-18). Minneapolis, MN: Learning Abroad Center, University of Minnesota and CAPA International Education.

Kalechstein, A. D., \& Nowicki Jr., S. (1997). A meta-analytical examination of the relationship between control expectancies and academic achievement: An 11-year follow-up to Findley and Cooper. Genetic, Social \& General Psychology Monographs, 123, 27-57.

Lefcourt, H. (1981). Locus of control: Current trends in theory and research. $2^{\text {nd }}$ ed. Hillsdale, NJ: Erlbaum.

Lewin, R. ed. (2009). The Handbook of Practice and Research in Study Abroad: Higher Education and the Quest for Global Citizenship. New York, NY: Routledge Press.

Marshall, M. A., \& Brown, J. D. (2004). Expectations and realizations: The role of expectancies in achievement settings. Motivation and Emotion, 28, 347-361.

McLeod, M. (1985). Locus of control and persistence in structured and unstructured preschool classrooms. Journal of Applied Developmental Psychology, 42, 493-505.

McLeod, M., \& Wainwright, P. (2009). Researching the study abroad experience. Journal of Studies in International Education, 13, 66-71.

Murphy, D., Sahakyan, N., Doua, Y.-Y., \& Sieloff Magnan, S. (2014). The impact of study abroad on the global engagement of university graduates. Frontiers: the Interdisciplinary Journal of Study Abroad, $24,1-24$.

NAFSA: Association of International Educators (2015). "New Horizons in International Education." Global Studies Literature Review Number 6. NAFSA: Association of International Educators. http://wnw.nafsa.org/Resource_Library_Assets/Networks/RS/Book_Reviews/Review_of_Global_Studies _Literature/Web. 1 May 2015.

Nowicki, S. (2014). A Manual for the Locus of Control Scales. Unpublished manuscript, Department of Psychology, Emory University, Atlanta GA.

Nowicki, S., \& Duke, M. P. (1974). A college and noncollege form of the Nowicki Strickland Internal External Control Scale. Journal of Personality Assessment, 38, 136-137.

Nowicki, S., \& Duke, M. P. (1983). The Nowicki-Strickland Life-Span Locus of Control Scales: Construct validation. In Lefcourt, H. (ed.). Research with the locus of control construct. Vol. 2. Developments and social problems. (pp. 9-51). New York, NY: Academic Press.

Rosenberg, M. (1965). Society and the adolescent self-image. Princeton, NJ: Princeton University Press. Rotter, J. B. (1954). Social learning and clinical psychology. New York, NY: Prentice-Hall. 
Mark McLead et al.

Rotter, J. B. (1966). Generalized expectancies for internal versus external control of reinforcement. Psychological Monographs, 80 (1, Whole 609).

Rotter, J. B. (1982). The development and applications of social learning theory: Selected papers. New York, NY: Praeger.

Rosenberg, M. (1965). Society and the adolescent self-image. Princeton, NJ: Princeton University Press.

Vande Berg, M., Paige, R. M., \& Lou, K. H., eds. (2012). Student learning abroad: what our students are learning, what they're not, and what we can do about it. Sterling, VA: Stylus. 